pag

Business School

WORKING PAPER SERIES

Working Paper

$2014-445$
On the liquidity of CAC 40 index options Market

Alain François-Heude

Ouidad Yousfi

http://www.ipag.fr/fr/accueil/la-recherche/publications-WP.html

IPAG Business School

184, Boulevard Saint-Germain

75006 Paris

France 


\title{
On the liquidity of CAC 40 index options Market
}

\author{
Alain François-Heude*\& Ouidad Yousfi ${ }^{\dagger}$
}

July 19, 2014

\begin{abstract}
The current paper shows that CAC 40 index options (namely PXA) display some illiquidity problems. We examine daily data on PXA trades between May 2005 and August 2012. The study evidences the presence of a considerable number of outstanding PXA contracts: most of these options are long-term maturity options and are deep in or deep out the money options.

To overcome the highlighted liquidity issues, we propose first to test the generalization of Gray and Whaley (1999) reset option introduced by François-Heude and Yousfi (2013). The main idea is to reset the strike price PXA option to a new strike price given by the CAC 40 value at a pre-agreed point of time. Then we provide some additional measures regarding the number the PXA strike price series and the PXA expiration dates. Finally, we test them on PXA market. Results show a significant and positive effect on the PXA liquidity.
\end{abstract}

Keywords: strike reset, option, PXA, liquidity, reset option.

\footnotetext{
${ }^{*}$ Montpellier Research in Management (MRM) in the University of Montpellier 2 (France). Email : alain.francois-heude@univ-montp2.fr

${ }^{\dagger}$ Montpellier Research in Management, (University of Montpellier 2, France) and associated at Gouvernance d'Entreprise Finance Appliquée et Audit GEF2A (ISG de Tunis, Tunisia) and at IPAG Research Lab (France). Corresponding email: ouidad.yousfi@univ-montp2.fr
} 
JEL Classification codes: G12, G13.

\section{Introduction}

It is commonly known that liquidity issue is a major concern for practitioners, financiers and policymakers. "Investors want three things from the markets: liquidity, liquidity and liquidity" (Handa and Schwartz, 1996). Liquidity is a key determinant of the price immediacy: if the market is liquid then investors can buy and sell assets quickly without bearing high transaction costs at a price close to the previously prevailing price (Cho and Engle, 1999).

In this sense, CAC 40 options, namely $\mathrm{PXA}^{1}$, are "the most heavily traded index options in the world" (Capelle-Blancard and Chaudhury, 2001), does this mean that PXA market is very liquid market?

Surprisingly, there are several issues covered in the CAC index market like for instance market efficiency, the liquidity effect of changes on the CAC 40 index, the determinants of implied volatility, etc.

However, there is few empirical evidence on the link between liquidity of CAC 40 index and options markets, particularly the liquidity of PXA market (see among others Deville and Riva, 2007; Roll et al., 2007; Deville, 2004; Capelle-Blancard and Chaudhury, 2001, 2007; Mittnik and Rieken, 2000; and Kamara and Miller, 1995). For instance, Deville

\footnotetext{
${ }^{1} \mathrm{PXA}$ is Paris indeX code for CAC 40 index options.
} 
(2004) tests the arbitrage relationships in option markets between August 2000 and July 2001 and determines the effective arbitrage profits obtained after constant execution delays. He concludes that profits are decreasing with the length of the delay. To measure the time needed to reach prices of no arbitrage conditions, he defines the "Time To Efficiency" (TEF) indicator and points out the positive effect of this indicator on efficiency.

In Deville and Riva (2007), a structural approach on the link between the duration of arbitrage opportunities and liquidity factors is considered. They examine the put-call parity deviations and the return to no arbitrage conditions. Under specific conditions, the speed of reversion of arbitrage profits depends on a set of variables that are related to liquidity, like for example the volume-dimension in the index constituent stocks and in the options market, the imbalance between put and call volume and the time to maturity. Furthermore, the addition or deletion of stocks in the CAC 40 index between 1997 and 2001 leads to liquidity variations. They are mainly explained with the direct cost of trading and the asymmetric information cost of transacting (Gregoriou, 2011) .

Implied volatility in CAC 40 options is also a puzzling issue. Few studies explore factors influencing implied volatility surface in the $C A C 40$ options' market (Kermiche, 2009 and 2008) and the dynamics of the factors influencing the deformation of implied volatility surface (Cont and Da Fonseca, 2002). Most of these studies are conducted on short-time periods.

To the best of our knowledge, Capelle-Blancard and Chaudhury (2001) are the only who analyze the efficiency of PXL options ${ }^{2}$ and the Euro adoption effect in Paris traded Options Market ${ }^{3}$ between January 2, 1997 and December 30, 1999. They conclude that PXL option are heavily traded. In addition, the Euro and PXL adoptions improved the transaction volume of CAC 40 options but did not necessarily enhance efficiency. In 2007,

\footnotetext{
${ }^{2}$ Before May 2005, there was PXL Paris IndeX Long options instead of PXA options.

${ }^{3}$ I was previously called Marché des Options Négociables de Paris MONEP.
} 
they examine the pattern and systematic tendencies of clustering in CAC 40 index option transaction prices between 1997 and 1999 and point out that the level of option premium, option volume and underlying asset volatility are important determinants of CAC 40 index option price clustering. Moreover, they observe a U-shaped pattern of clustering based on intraday and intra-year data. Finally, the liquidity effect is explained by the volume effect.

The current paper is the first one conducted on the CAC40 index options after 2005 that focuses on PXA liquidity based on a large sample size over a long period of time (PXA trades between May 2005 and August 2012 ). Our results are not consistent with CapelleBlancard and Chaudhury (2001) and point out the presence of liquidity problems in PXA market particularly options with long-term expiration dates and deep in or deep out the money options.

The study is related to the body of work on options' liquidity, particularly on microstructure and options pricing. Most studies analyze how the liquidity of the underlying asset could affect options' liquidity. For instance, Brenner et al. (2001) consider non-tradable versus tradable currency options issued by the Bank of Israel. They provide evidence that liquidity has effect on the pricing of these options. Garleanu et al. (2009), and Bollen and Whaley (2004), find a link between buying and selling flows and the option's type (call, index put options or individual or single stock options). As option is a contingent asset, other studies argue that the liquidity of the underlying asset may have an effect on the pricing of the option. They pay particular attention to the spot liquidity risk in the pricing of options. For instance, Frey (1998) shows that large agents whose trades may lead to a down/upward movements in the asset price, can replicate the payoff of a derivative security. Cho and Engle (1999) propose the "derivative hedge theory" in which the liquidity and spread can be determined by the spot market if the investors in the derivative market can hedge their positions using the underlying asset. They show that option market spreads are positively 
related to bid-ask spreads of $S \& P 100$ index options. Most of these studies are conducted on non-European markets and cover a short-period data analysis.

To overcome the liquidity problems, we test the generalization of Gray and Whaley (1999) reset option introduced by François-Heude and Yousfi (2013). The main idea is to reset the PXA strike price to a new strike price that is given by the value of CAC40 index. The reset is set up at a pre-agreed time point t. The intuition is to enable the holders of ITM options to replace them with ATM ones to lock in their profits given by the difference between the strike price and the then current value of the underlying asset. The profit has to be deposited into the Clearing House. The holders of OTM options can replace the less liquid options with more liquid ones that are ATM in exchange for cost paid to the Clearing house.

This paper is therefore related to the extensive literature on valuation problems for options, particularly options with either reset condition or a forward-start condition (see among others Haug and Haug 2001; Gray and Walhey, 1999; Rubinstein, 1991, etc...). It proposes a combination of both conditions and provides an empirical validation of the generalization of Gray and Whaley reset option presented by François-Heude and Yousfi (2013). They propose a combined extension of reset and forward-start options of Gray and Whaley (1999) and Rubinstein (1991), in which the strike price is automatically reset to the underlying asset price before the option matures. The reset is done whether the strike price is lower or higher than the underlying index value. Consequently, at a pre-agreed point of time $t$, OTM and ITM options are replaced by ATM options in exchange for deposits into the Clearing House. These deposits can be considered as the cost paid by the holders of OTM options for obtaining more liquid options or the profit of the holders of ITM options who want to lock in their profits at a certain time point.

The contribution of this paper is double. First, it provides evidence that the PXA market 
displays some liquidity problems. Unlike previous studies, our data cover a long period of time. Second, it tests the generalization of Gray and Whaley reset option introduced by François-Heude and Yousfi (2013) and provides some practical recommendations to overcome these liquidity problems in several ways.

The rest of this paper is organized as follows. Section 2 presents PXA data and highlights several illiquidity problems. Section 3 provides some practical recommendations. We conclude in Section 4.

\section{Stylized facts on $C A C 40$ index option}

\subsection{Data}

Before January 1999, CAC 40 index options, namely PXL, had been available for two halfyearly expiration dates and consecutive strike prices had been scaled by 150 index points (hereafter ip). The contract size had been equal to FRF $50 \times$ theCAC40indexandtheminimumprice fluctuationhadbeenequal FRF 50.

Because of the EURO adoption, PXL expiration dates changed and became eight expiration dates (3 monthly, 3 quarterly and 2 half-yearly). The consecutive strike prices were separated by 50 ip for monthly expirations, 100 ip for quarterly expirations and 200 ip for half-yearly expirations. The PXL contract size was EUR $1 \times$ the CAC 40 index and the PXL tick size was 0.10 ip while the cash settlement was equal to the difference between the exercise price and the expiration settlement index time EUR 1. PXL option series were organized in at least three strike prices available: one around the CAC 40 index value and two OTM strikes closest to the CAC 40 index value. ITM options are usually automatically exercised at expiration, unless the option's holder decides not to do. 
In May 2005, PXL options were replaced with PXA options. The new option contract has thirteen expiration dates ( 3 monthly, 7 quarterly and 3 yearly $)^{4}$ while the consecutive strike prices are organized in six intervals: A (25 ip), B (50 ip), C (100 ip), D (200 ip), E (400 ip), and F (800 ip). The PXA contract size is equal to EUR 10×the CAC 40 index and the PXA tick size is equal to 1 ip. ${ }^{5}$

The current study focuses on PXA options and is drawn on a time-stamped record of every trade in the French options market MONEP (Marché des Options Négociables de Paris), in SBF (Société Bourse de France) and in NYSE-EURONEXT, and the transaction volume for all call and put options.

Some features of these option contracts have changed with the shift to the Euro and to the PXA contract. The data provide information on the number of trades, option's type (call/put), option's maturity, strike price, transaction volume, open interest (hereafter OI), the underlying closing and opening prices, and the highest and lowest prices.

The dataset is hand-collected from the following sources:

- MATIF (Marché à Terme International de France) and MONEP between January, 1999 and April, 2009.

- BDM (Base de Données de Marché) of the SBF between December, 1999 and March, 2001.

- NYSE-EURONEXT databases between March, 2003 and August, $2012{ }^{6}$.

\footnotetext{
${ }^{4}$ Notice however, that many PXL options did not mature by May 2005. Consequently, many expiration dates were kept: between May 9, 2005 and May 17, 2007, the number of expiration dates was twenty two ( 3 monthly and 19 quarterly) however the quarterly expiration dates of more than 2 years were replaced by 3-year expiration dates (see table 6 for more information).

${ }^{5}$ More details are available in Appendix A.

${ }^{6}$ Some of Euronext data are available at the following links:

http://nysetechnologies.nyx.com/Data-Products/nyse-liffe-nexthistory-index-derivatives-eod

http://www.liffe.com/reports/eod?item $=$ Histories\&archive $=994191131$

https://globalderivatives.nyx.com/nyse-liffe/daily-statistics
} 
We filter out PXL options that mature before May 2005 and keep all PXA options: there are 1878 trade-dates between May, 2005 and August, 2012. In addition, to take into account the $P X L / P X A$ adoption effects of : we screen the $P X L$ data and eliminate transactions' volume between May 9, 2005 and August 19, 2005 but keep OI of August 22, 2005. There are some missing data on trades between May and December 20097. The remaining data is selected regarding whether it belongs to the market months ${ }^{8}$ or not. All data that are not in the market month are not included in our sample: we obtain then 84 market months which counts 1793 trade dates.

If we reorganize our data according to:

- the expiration dates, we obtain 27314 series;

- the strike series, we have 821989 series;

- the option's type (call and put), the number of series increases significantly to achieve 1643978.

Our data show that PXA volume is significantly high (total PXA volume is equal to 48 164269 contracts): The number of daily trades considerably varies between 170 (minimum) and 4367 trades (maximum) which results on a large standard deviation (see table 2). Thus, according to this first approach, we are tempted to join Capelle-Blancard and Chaudhury (2001) and conclude that like PXL options, PXA ones are heavily traded between 2005 and 2012 in spite of the financial crisis.

\footnotetext{
${ }^{7}$ The PXL/PXA transfer leads to a decrease of the number of open maturities from 22 expirations dates to 13 expiration dates. Some maturities of the previous regime were kept to facilitate the transfer. However, we delete them of our data. We exclude the following maturities: June 2009, September 2009, March 2010, June 2010 and March 2011. Consequently, our data are missing:

- The OI of the June 2009 maturity (4250 contracts).

- The OI (1250 contracts) and the traded volume (253) of the June 2010 maturity.

${ }^{8}$ The market month $m$ starts the first Monday following the third Friday of the $(m-1)^{t h}$ month and ends up the third Friday of the current month $(m)$.
} 
In addition, the database highlights that put options represent $55.54 \%$ of the total PXA volume. This could be explained by the downward trend in the market particularly due to the financial subprime crisis. The variations of PXA volume and CAC 40 index are positively associated (see figure 1) that may evidence the link between the liquidity of the option and the underlying asset.

\subsection{Descriptive statistics}

To analyze the liquidity of PXA market, we focus on outstanding positions and scrutinize OI.

Figure 2 represents CAC 40 index, PXA volume and OI between May, 2005 and August, 2012. It shows that the three series vary similarly: they increase and decrease almost simultaneously. Furthermore, the variations of PXA total volume and OI are positively associated. For instance, they were increasing between September, 2005 and September 2007. Then, they fluctuated until June 2009 and suddenly decreased (see figures 1 and 2). The number OI significantly varies (the minimum is equal to 312501 and the maximum is equal to 1511329$)$. It is straightforward to see that the level of outstanding positions is considerably large which may signal the presence of liquidity problems.

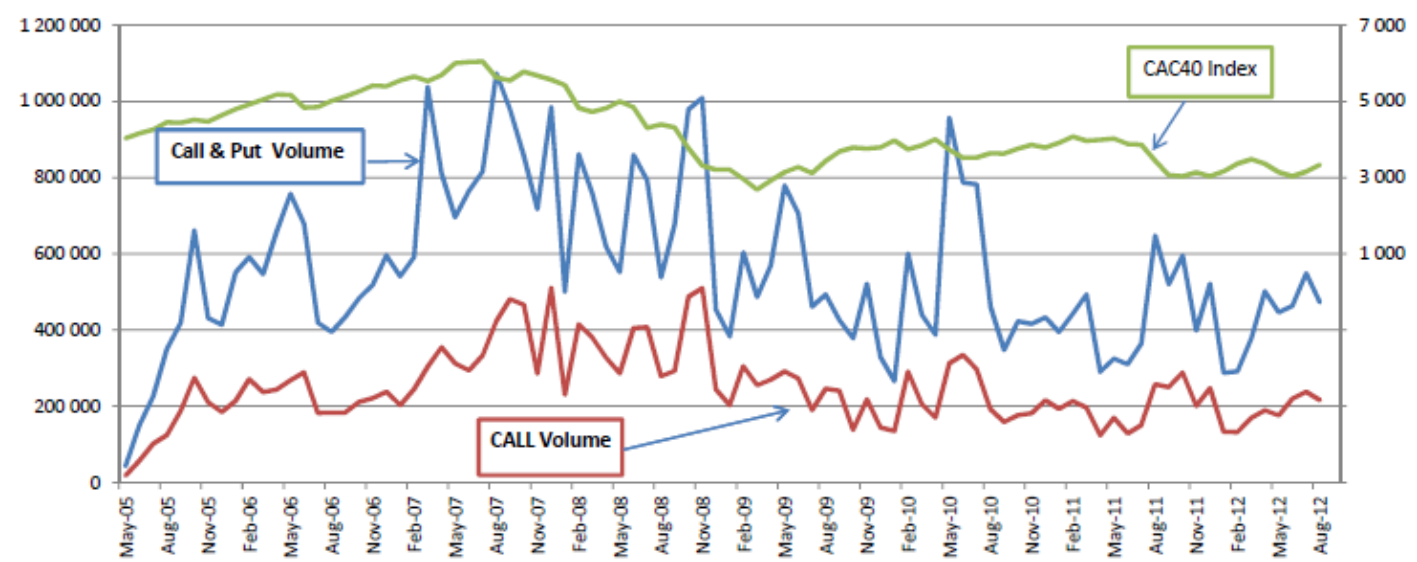


Figure 1: Monthly volume statistics of PXA (left-axis) and CAC 40 index (right-axis) between May, 2005 and August 2012.

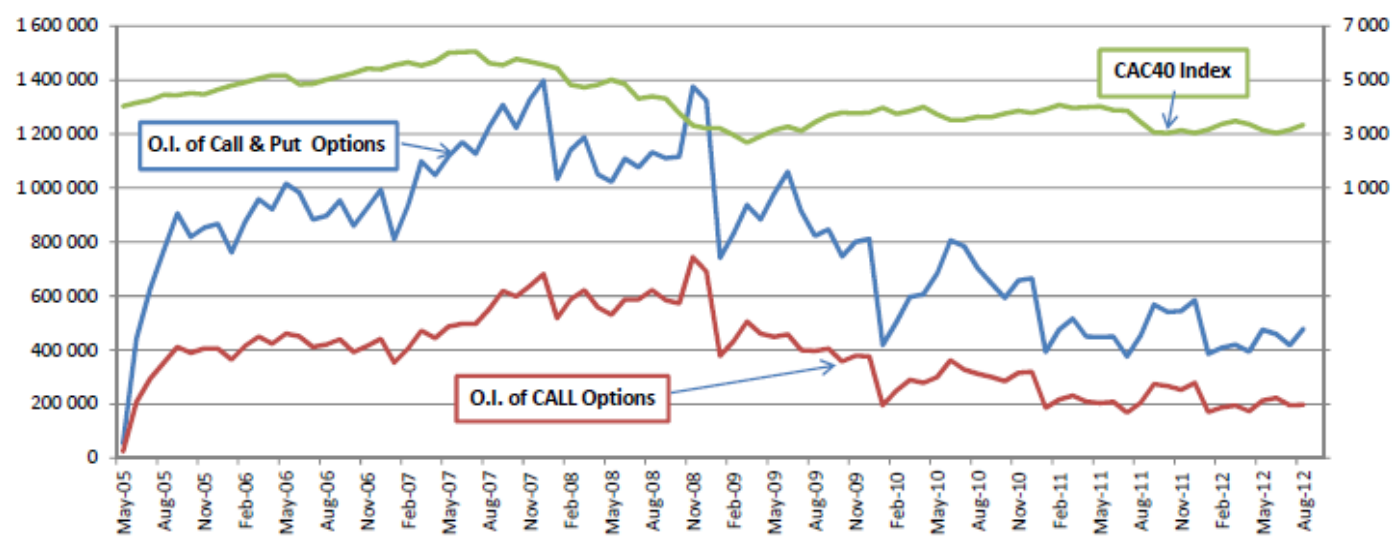

Figure 2: Monthly Statistics of PXA Open interest (left-axis) and CAC40 index (right-axis) between May, 2005 and August, 2012.

Descriptive statistics on monthly and daily data are respectively summarized in tables 1 and 2. $C A C 40$ index option market displays a high level of liquidity if we must consider the high trade volume and the large number of trades. However the number and volume of OI are considerably high too. Indeed, the average monthly OI of calls and puts was increasing between September 2005 and March 2009, after that it decreased dramatically. In December 2007, the number of open contracts went up and reached 1397427 . Also, OI is highly dispersed (283 395) which tempts to confirm the liquidity problem we suspected. 


\begin{tabular}{|c|c|c|c|c|c|c|c|c|c|}
\hline \multirow[t]{2}{*}{ Monthly data } & \multicolumn{3}{|c|}{ Volume } & \multicolumn{3}{|c|}{ Trades } & \multicolumn{3}{|c|}{ O.I. } \\
\hline & Call & Put & Call+Put & Call & Put & $\mathrm{Call}+\mathrm{Put}$ & Call & Put & $\mathrm{Call}+\mathrm{Put}$ \\
\hline Mean & 254939 & 318445 & 573384 & 9425 & 10127 & 19552 & 254939 & 318445 & 573384 \\
\hline Median & 239278 & 294068 & 521557 & 8416 & 9192 & 17449 & 239278 & 294068 & 521557 \\
\hline Standard deviation & 90797 & 121738 & 198818 & 3515 & 3778 & 7129 & 90797 & 121738 & 198818 \\
\hline Max & 511248 & 734758 & 1073430 & 24598 & 30085 & 54683 & 511248 & 734758 & 1073430 \\
\hline Min & 123437 & 131256 & 266019 & 5293 & 5437 & 10856 & 123437 & 131256 & 266019 \\
\hline
\end{tabular}

Table 1: Descriptive statistics on PXA options over 84 market months between May 22, 2005 and August 20, 2012. Monthly data on Volume ( $84 \mathrm{obs})$, trades (78 obs) and OI ( $84 \mathrm{obs)}$ where obs is the number of observations

\begin{tabular}{|c|c|c|c|c|c|c|c|c|c|}
\hline \multirow[t]{2}{*}{ Daily data } & \multicolumn{3}{|c|}{ Volume } & \multicolumn{3}{|c|}{ Trades } & \multicolumn{3}{|c|}{ O.I. } \\
\hline & Call & Put & Call+Put & Call & Put & $\mathrm{Call}+\mathrm{Put}$ & Call & Put & $\mathrm{Call}+\mathrm{Put}$ \\
\hline Mean & 11944 & 14919 & 26862 & 442 & 475 & 917 & 392553 & 432067 & 824620 \\
\hline Median & 10359 & 12860 & 23794 & 390 & 409 & 808 & 394934 & 445585 & 846149 \\
\hline Standard deviation & 7282 & 10174 & 15255 & 234 & 264 & 472 & 147298 & 144746 & 285304 \\
\hline $\operatorname{Max}$ & 82155 & 106871 & 152896 & 1798 & 2704 & 4367 & 817854 & 778441 & 1511329 \\
\hline Min & 473 & 836 & 1611 & 52 & 93 & 170 & 145223 & 167278 & 312501 \\
\hline
\end{tabular}

Table 2: Descriptive statistics on PXA options over 1793 market days between May 22, 2005 and August $20,2012$.

Daily data on Volume (1793 obs), trades (1620 obs) and OI (1793 obs) where obs is the number of observations

To go further and better assess the liquidity problems, we analyze correlation between open positions of calls and puts in both basis daily and monthly (see tables 3 and 4). We find a strong and positive correlation between put and call OI which implies that the increase of 
PXA volume has a positive effect on the number of OI and vice versa.

\begin{tabular}{|c|c|c|c|}
\hline \multicolumn{2}{|c|}{ Linear Correlation } & \multicolumn{2}{|c|}{ Call } \\
\cline { 3 - 4 } \multicolumn{2}{|c|}{} & monthly Vol & monthly PO \\
\hline \multirow{2}{*}{ Put } & monthly Vol & 0,74 & 0,51 \\
& monthly OI & 0,67 & 0,91 \\
\hline
\end{tabular}

Table 3: Correlation between monthly Volume and monthly OI over 84 market months.

\begin{tabular}{|c|c|c|c|}
\hline \multicolumn{2}{|c|}{ Linear correlation } & \multicolumn{2}{|c|}{ Call } \\
\cline { 2 - 4 } & daily Vol & daily PO \\
\hline \multirow{2}{*}{ Put } & daily Vol & 0,51 & 0,30 \\
& daily OI & 0,40 & 0,93 \\
\hline
\end{tabular}

Table 4: Correlation between daily options Volume and OI over 1793 trading days.

\subsection{Liquidity issues}

To analyze PXA option liquidity, we calculate some liquidity measures. The survey of the literature on liquidity show the presence of many measures of option's liquidity, like for example width, depth and immediacy ${ }^{9}$. However, they cannot be used in daily dataset

\footnotetext{
${ }^{9}$ The main measures of option liquidity are:

- Width which is captured by the bid-ask spread and other transaction costs generated by the trade of a certain amount of the asset.

- Depth is the volume that can be traded at the observed bid-ask quotes

- Immediacy measures how quickly an order with a given size and cost can be executed in the market.

- Resiliency captures how quickly asset prices and quotes react to large order flow imbalances or under asymmetric information to reach the equilibrium levels.
}

They are used in intraday data given by limit order book. 
analysis.

To the best of our knowledge, there are no previous studies on index option liquidity, in order to identify the source of the liquidity problems we calculate the following ratios:

- PXA Volume/number of Trades ratio to measure the average size of a PXA trade.

- OI/Volume ratio to analyze the relationship between the volume of open positions and the total PXA volume. This ratio assesses the market trend. However, open positions are calculated end of the day while PXA volume results from transacting through selling and buying orders during all the day. Accordingly, it is better to analyze the OI variations (see table 5).

\begin{tabular}{|lccc|}
\hline \multicolumn{1}{|c}{ Monthly } & Volume/ Trades & OI/Volume & $\Delta$ OI/Volume \\
\hline $\mathrm{N}$ & 80 & 88 & 87 \\
Mean & 33.88 & 1.52 & 0.0051 \\
Median & 33.28 & 1.45 & 0.0354 \\
Standard deviation & 18.77 & 0.46 & 0.4201 \\
Max & 171.29 & 2.95 & 2.5985 \\
Min & 15.57 & 0.70 & -1.5204 \\
\hline
\end{tabular}

Table 5: Descriptive statistics on liquidity measures for call and put options over 84 market months. (No available data between May, 2009 and December, 2009)

Figure 3 shows that monthly average size of trade decreased by $62.36 \%$ from May, 2005 to August, 2012 which must be considered carefully as no data available on PXA trades between May, 2009 and December, 2009. Notice however that $\Delta O I / V$ olume ratio does not 
vary considerably. The ratio decreases form 9.1938 in May 2005 to 0.13 in August 2012 but the standard deviation is not very large. One explanation is that PXA volume increases more rapidly than open positions showing that PXA options are heavily traded.

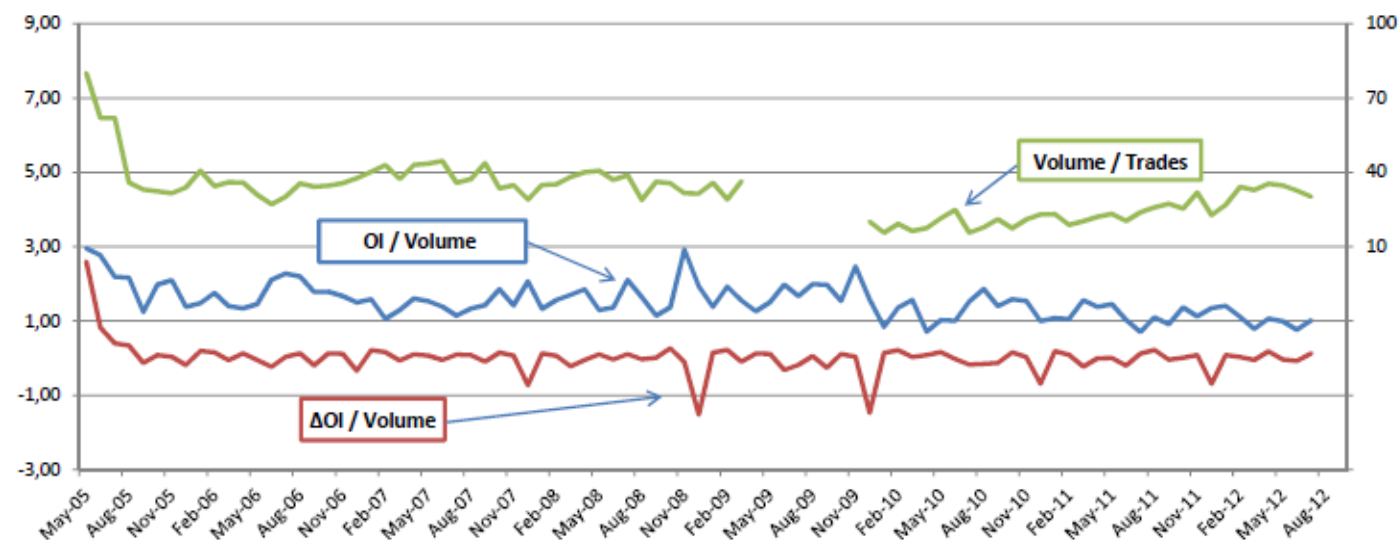

Figure 3: Variations of Volume/Trades Vol/TRA(right-axis), OI/Volume OI/Vol and $\Delta$

OI/Vol $\Delta$ OI/Vol monthly ratios (left-axis) between May, 2005 and August 2012.

To identify those options displaying liquidity issues, we examine the distribution of PXA trades and OI over strike price series, PXA expiration dates and moneyness.

The number of PXA series is the sum of the call and put series. We recall that the number the PXA call series is equal to the PXA put series. They are symmetric with respect to ATM series. The following tables present the PXA series for call or put options. 

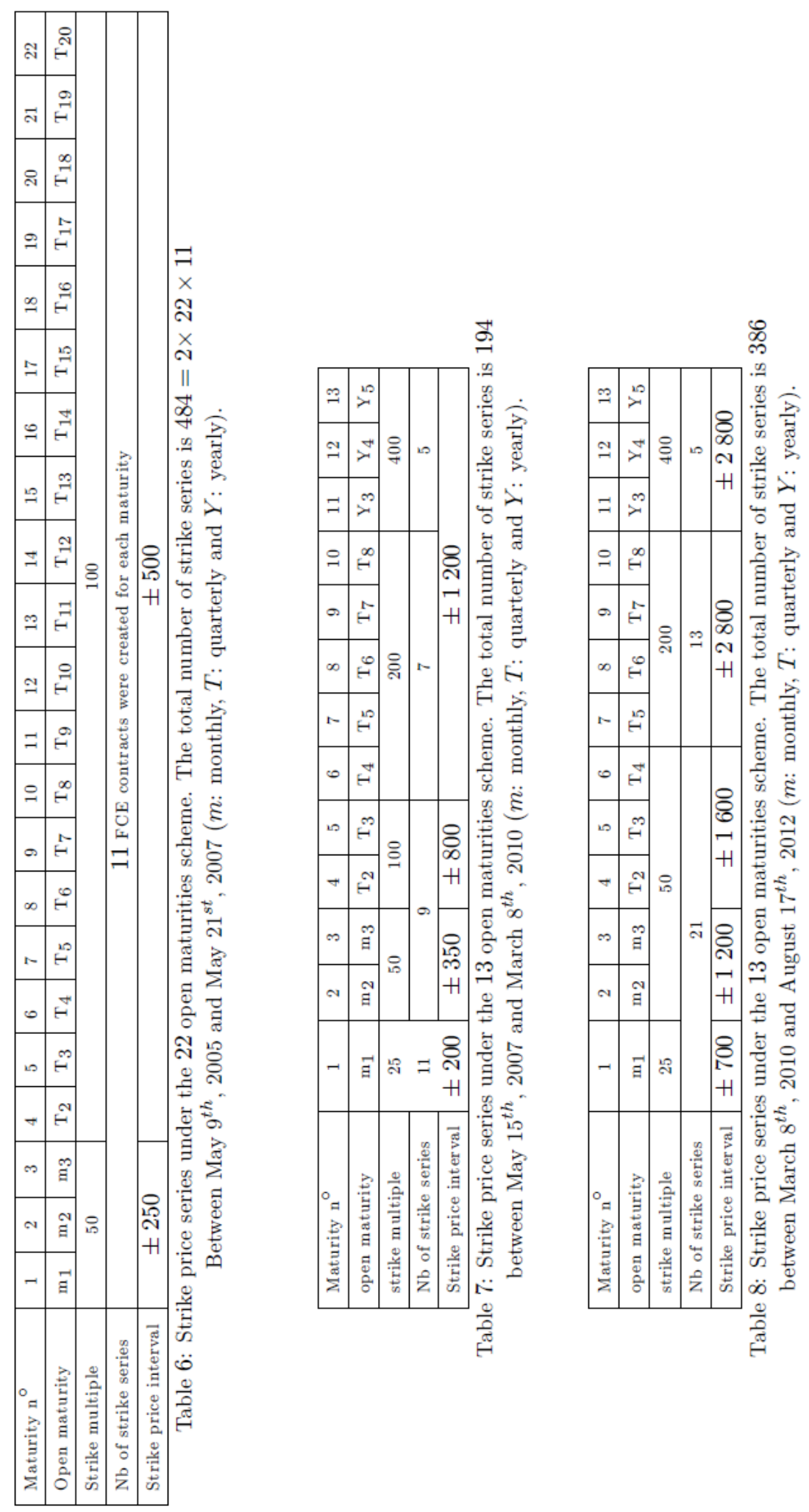
Between May 9, 2005 and May 17, 2007, the number of quarterly expiration dates was 19 (see table 6). After May 21, 2007, the quarterly expiration dates of more than 2 years $T_{i}, i=8, \ldots, 20$ were replaced by 3 -year expiration dates $Y_{i}, i=3,4,5$. Then, the number of strike price series dramatically decreased from 242 to 97 strike series but it rises again and becomes 193. It is straightforward to see that strikes series decrease when open maturities become longer (more than 2 years) despite the fact that these maturities become more concentrated (see table 8).

Also, tables 6, 7 and 8 show that strike price interval increased significantly. For instance, for the spot monthly maturity $m_{1}$, the interval scale becomes three time what is was under the 22 open maturities scheme. The intuition is to enable traders to take into account the high volatility of CAC40 index: when it varies, this leads to the creation of new strike series around ATM to adjust traders' positions. Indeed, as long as open position exists, the strike series will not disappear.

\subsection{Expiration dates/Strike price series/Moneyness}

As call and put options are symmetric, we focus on the distribution of one type PXA options. The following figure provides a summary of the distribution of series and maturities between September 2005 and August 2012. The number of quoted series is significantly superior to the theoretical number of series $(242,97$ and 193 given respectively by tables 6,7 and 8). It suddenly decreased in May 2007. One explanation is the transferring of positions from PXL to PXA. In addition, series that did not expire before 2005, were kept which may increase the volatility. Another explanation is the setup of new PXA maturity scheme: since 2005, the number of expiration date contracts has been decreased from 22 to 13 . Unlike the distribution of PXA contracts with positive OI, the variations of PXA contracts with 
positive volume were stable over the whole period. However, the number of illiquid series is significantly larger than the number of liquid series. All these findings highlight the presence of illiquidity problems.

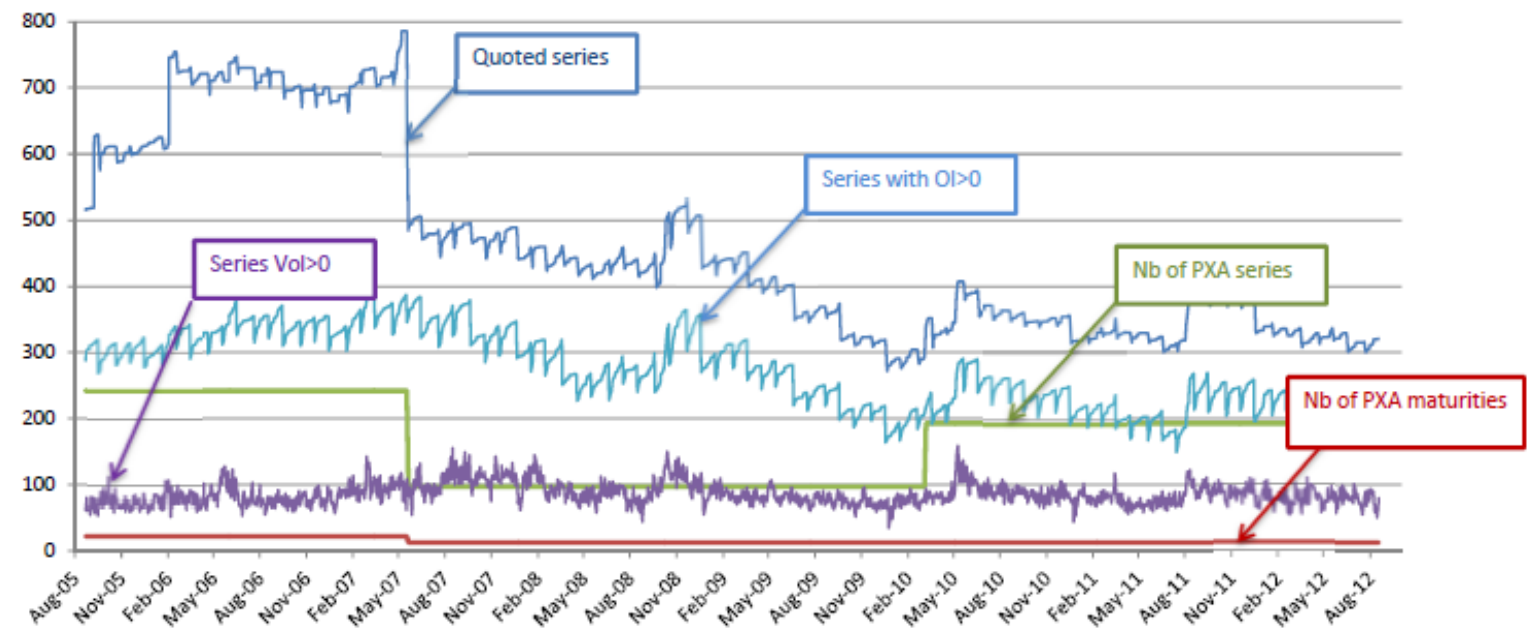

Figure 4: Distribution of PXA series between May, 2005 and August, 2012.

To examine these issues, we divide PXA maturities into 5 categories according to the following criteria:

\begin{tabular}{|c|c|c|c|c|}
\hline Term & Category & delivery date & 22 scheme & 13 scheme \\
\hline Very & 1 & $0<T \leq 1 m$ & \multicolumn{2}{|c|}{$\mathrm{m}_{1}$} \\
\hline Short & 2 & $1 m<T \leq 3 m$ & \multicolumn{2}{|c|}{$\mathrm{m}_{2}$ and $\mathrm{m}_{3}$} \\
\hline Medium & 3 & $3 m<T \leq 1 y$ & $\mathrm{~T}_{2}, \mathrm{~T}_{3}$ and $\mathrm{T}_{4}$ \\
\hline Long & 4 & $1 y<T \leq 3 y$ & $\mathrm{~T}_{5}-\mathrm{T}_{12}$ & $\mathrm{~T}_{5}-\mathrm{T}_{8}$ and $\mathrm{Y}_{3}$ \\
\hline Very long & 5 & $3 y<T \leq 5 y$ & $\mathrm{~T}_{13}-\mathrm{T}_{22}$ & $\mathrm{Y}_{4}$ et $\mathrm{Y}_{5}$ \\
\hline
\end{tabular}

Table 9 : Categories of PXA expiration dates $(m$ : month, $y$ : year) 
Taking into account these criteria changes the distribution of PXA call and put series and provides interesting results. We find that short term maturity categories (1 and 2) capture the highest number of PXA contracts: $83.37 \%$ of PXA options mature before 3 months (see table 10). Long maturity index options display some liquidity problems: less than $3.5 \%$ of PXA contracts in our data belong to the categories 4 and 5 (see appendix B for further statistics on call/put distribution).

\begin{tabular}{|l|c|c|c|c|c|}
\hline \multicolumn{1}{|c|}{ Maturity category } & 1 & 2 & 3 & 4 & 5 \\
\hline Mean & $43.71 \%$ & $39.66 \%$ & $13.50 \%$ & $2.70 \%$ & $0.44 \%$ \\
Median & $44.12 \%$ & $38.46 \%$ & $13.46 \%$ & $1.70 \%$ & $0.05 \%$ \\
Standard deviation & $7.67 \%$ & $8.80 \%$ & $5.17 \%$ & $2.83 \%$ & $0.79 \%$ \\
Max & & & & & \\
Min & $60.95 \%$ & $60.00 \%$ & $29.56 \%$ & $13.65 \%$ & $4.15 \%$ \\
Average cumulative frequency & $43.71 \%$ & $83.37 \%$ & $96.87 \%$ & $99.56 \%$ & $100 \%$ \\
\hline
\end{tabular}

Table 10 : Descriptive statistics on the distribution of PXA options

Hereafter, we focus on the moneyness of PXA options and analyze the distribution of near money options. Strike series are similar for PXA call and put options and are symmetric with respect to ATM strike. Let us assume that $S_{t}$ is the value of the underlying CAC 40 index at time point $t, X$ is the strike price of the PXA option and $\Delta$ is the interval scale where $\Delta=0.1$. The moneyness scale is given by:

$$
\left|\frac{S_{t}-X}{X}\right| \leq \alpha \frac{\Delta}{2} \text { where } \alpha \in \mathbb{N}
$$


Accordingly, we consider that ATM options satisfy the following:

$$
\frac{S_{t}}{X}=1 \pm 5 \%
$$

Then, we focus on the distribution of ITM, OTM and ATM options along the moneyness scale $\alpha \frac{\Delta}{2}$. Results are in tables 11, 12 and 13 .

\begin{tabular}{|l|l|l|l|l|l|l|l|l|}
\hline Call and Put & $\pm 1 \frac{\Delta}{2}$ & $\pm 2 \frac{\Delta}{2}$ & $\pm 3 \frac{\Delta}{2}$ & $\pm 4 \frac{\Delta}{2}$ & $\pm 5 \frac{\Delta}{2}$ & $\pm 6 \frac{\Delta}{2}$ & $\pm 7 \frac{\Delta}{2}$ & $\pm 8 \frac{\Delta}{2}$ \\
\hline ATM options & $4.11 \%$ & $8.18 \%$ & $12.191 \%$ & $16.10 \%$ & $19.88 \%$ & $23.56 \%$ & $27.15 \%$ & $30.57 \%$ \\
\hline & $\pm 9 \frac{\Delta}{2}$ & $\pm 10 \frac{\Delta}{2}$ & $\pm 11 \frac{\Delta}{2}$ & $\pm 12 \frac{\Delta}{2}$ & $\pm 13 \frac{\Delta}{2}$ & $\pm 14 \frac{\Delta}{2}$ & $\pm 15 \frac{\Delta}{2}$ \\
\hline
\end{tabular}

Table 11: The percentage of near the money PXA options according

to the moneyness scale $\alpha \Delta$

\begin{tabular}{|c|c|c|c|c|c|c|c|}
\hline$\alpha \Delta$ & 0.4 & 0.5 & 0.6 & 0.7 & 0.8 & 0.9 & 1.0 \\
\hline ATM $\pm \alpha \frac{\Delta}{2}$ & $<0.45$ & $0.45-0.55$ & $0.55-0.65$ & $0.65-0.75$ & $0.75-0.85$ & $0.85-0.95$ & $0.95-1.05$ \\
\hline Call options & $0.92 \%$ & $1.42 \%$ & $3.23 \%$ & $8.91 \%$ & $25.13 \%$ & $47.10 \%$ & $12.27 \%$ \\
\hline Put options & $0.29 \%$ & $0.03 \%$ & $0.04 \%$ & $0.21 \%$ & $1.03 \%$ & $11.30 \%$ & $37.63 \%$ \\
\hline Total options & $0.57 \%$ & $0.65 \%$ & $1.46 \%$ & $4.08 \%$ & $11.75 \%$ & $27.21 \%$ & $26.35 \%$ \\
\hline
\end{tabular}




\begin{tabular}{|c|c|c|c|c|c|c|}
\hline$\alpha \Delta$ & 1.1 & 1.2 & 1.3 & 1.4 & 1.5 & 1.6 \\
\hline ATM $\pm \alpha \frac{\Delta}{2}$ & $1.05-1.15$ & $1.15-1.25$ & $1.25-1.35$ & $1.35-1.45$ & $1.45-1.55$ & $>1.55$ \\
\hline Call options & $0.61 \%$ & $0.12 \%$ & $0.06 \%$ & $0.05 \%$ & $0.03 \%$ & $0.15 \%$ \\
\hline Put options & $21.81 \%$ & $10.84 \%$ & $6.23 \%$ & $4.12 \%$ & $2.29 \%$ & $4.17 \%$ \\
\hline Total options & $12.39 \%$ & $6.08 \%$ & $3.49 \%$ & $2.31 \%$ & $1.29 \%$ & $2.39 \%$ \\
\hline
\end{tabular}

Table 12: The distribution of the PXA volume according to the moneyness scale $\alpha \Delta$

\begin{tabular}{|c|c|c|c|c|c|c|c|}
\hline$\alpha \Delta$ & 0,4 & 0,5 & 0,6 & 0,7 & 0,8 & 0,9 & 1,0 \\
\hline $\mathrm{ATM} \pm \alpha \frac{\Delta}{2}$ & $<0.45$ & $0.45-0.55$ & $0.55-0.65$ & $0.65-0.75$ & $0.75-0.85$ & $0.85-0.95$ & $0.95-1.05$ \\
\hline Call options & $13.26 \%$ & $5.05 \%$ & $6.96 \%$ & $10.14 \%$ & $13.95 \%$ & $15.95 \%$ & $11.02 \%$ \\
\hline Put options & $8.95 \%$ & $2.52 \%$ & $3.00 \%$ & $3.62 \%$ & $4.99 \%$ & $8.85 \%$ & $13.32 \%$ \\
\hline Total options & $11.00 \%$ & $3.73 \%$ & $4.89 \%$ & $6.73 \%$ & $9.25 \%$ & $12.23 \%$ & $12.23 \%$ \\
\hline
\end{tabular}

\begin{tabular}{|c|c|c|c|c|c|c|}
\hline$\alpha \Delta$ & 1.1 & 1.2 & 1.3 & 1.4 & 1.5 & 1.6 \\
\hline ATM $\pm \alpha \frac{\Delta}{2}$ & $1.05-1.15$ & $1.15-1.25$ & $1.25-1.35$ & $1.35-1.45$ & $1.45-1.55$ & $>1.55$ \\
\hline Call options & $6.73 \%$ & $4.65 \%$ & $3.42 \%$ & $2.58 \%$ & $1.93 \%$ & $4.36 \%$ \\
\hline Put options & $12.39 \%$ & $9.77 \%$ & $7.51 \%$ & $5.94 \%$ & $4.58 \%$ & $14.57 \%$ \\
\hline Total options & $9.70 \%$ & $7.33 \%$ & $5.56 \%$ & $4.34 \%$ & $3.32 \%$ & $9.71 \%$ \\
\hline
\end{tabular}

Table 13: The distribution of the PXA OI according to the moneyness scale $\boldsymbol{\alpha} \boldsymbol{\Delta}$

However, table 11 provides aggregate results for ATM options of both PXA calls and puts. To examine the distribution of ATM options, we focus on the distribution of the PXA volume and OI along the 5 maturity categories. The main result of table 12 is that only $12.27 \%$ (respectively $37.63 \%$ ) of call (respectively put) options are ATM while almost $72 \%$ 
(respectively $33 \%$ ) are OTM. In conclusion, $65.95 \%$ of PXA options are near the money.

Table 13 shows that $65.31 \%$ (respectively 54.76\%) of PXA call (respectively put) series are OTM. Unlike PXA volume, OI are widely dispersed along the moneyness scale $\alpha \Delta$. For instance, $12.32 \%$ of OI are ATM, $21.93 \%$ are near the money options and $20.71 \%$ are deep in and out of the money. The recommendation to replace all the OTM options with ATM ones seems again very intuitive (Appendix $C$ provides more details on the distributions of the volume and OI along maturity categories).

In conclusion, we evidence that only near ATM PXA options with short-term expiration dates are liquid. As PXA are European options, options' holders have to wait until the options mature to decide or not to exercise them which could explain to a large extent the large number of open positions in long term maturity PXA options available in the market and their low number of trades. In line with Frnaçois-Heude and Yousfi (2013), it would be interesting for investors who hold deep OTM or ITM options to reset the strike price to a strike price equal to the value of CAC 40 index at a pre-agreed time point $t$. This will help ITM holders to lock in their profit and the OTM holders to replace their options with more liquid options.

\section{How to improve PXA liquidity?}

Regarding the liquidity problems discussed in the previous section, we advance three practical recommendations to improve the liquidity of CAC 40 index options.

First, we propose to put into practice the generalization of Gray and Whaley (1999) reset option introduced by François-Heude and Yousfi (2013). The main idea is to replace all deep in ITM and OTM option with PXA options that are ATM. To do so, we propose to reset the strike price to a new strike price that is equal to the value of the CAC 40 index. 
For ITM holders, they will deposit their profit into the Clearing House. However, for OTM holders replacing their options with ATM ones is costly. In practice, this comes to reset each third Friday of the market month, the strike price to the then value of the underlying index.

Second, as strike price series that are deep ITM/OTM are the less liquid strike price series, we recommend to keep the keep 5 intervals $A, B, C, D$ and $E$ but to scale them differently such that all interval scales become 25 ip

Third, despite that the number of expiration dates has been decreased, our results highlight that long-term expiration dates are less liquid than short-term ones. Accordingly we propose considering 10 PXA expiration dates rather than the 13 current expiration dates:

- Three spot contracts that mature before 3 months;

- Three quarterly contracts that mature between 3 months and 1 year (March, June and September cycles);

- Four yearly contracts that mature between 2 years and 5 years (December cycles).

Finally, for each strike price series, it is better to keep three strike series in each scale: 
ATM, ITM and OTM.

\begin{tabular}{|c|c|c|c|c|c|c|}
\hline Scale & Interval & $\mathrm{m}_{1}$ & $\mathrm{~m}_{2} \cdot \mathrm{m}_{3}$ & $\mathrm{~T}_{2} \cdot \mathrm{T}_{3} \cdot \mathrm{T}_{4}$ & $\mathrm{Y}_{2} \cdot \mathrm{Y}_{3}$ & $\mathrm{Y}_{4} \cdot \mathrm{Y}_{5}$ \\
\hline & & 01-12 & 01-12 & 03-06-09 & Dec & Dec \\
\hline A & 25 & $\mathrm{ATM} \pm 1$ & & \multirow{5}{*}{$\mathrm{ATM} \pm 1$} & & \\
\hline B & 50 & & $\mathrm{ATM} \pm 1$ & & & \\
\hline $\mathrm{C}$ & 100 & & & & \multirow{3}{*}{$\mathrm{ATM} \pm 1$} & \\
\hline $\mathrm{D}$ & 200 & & & & & \\
\hline $\mathrm{E}$ & 400 & & & & & $\mathrm{ATM} \pm 1$ \\
\hline
\end{tabular}

Table 14: The distribution of PXA strike price series.

To analyze the impact of these recommendations on the PXA liquidity, we identify open positions of $P X A$ series that are not ATM. August series that mature in 2012, expired in August $17^{t h}, 2012$. There are still some open positions for the remaining 12 PXA maturities. For each contract, we define the ATM strike price. 


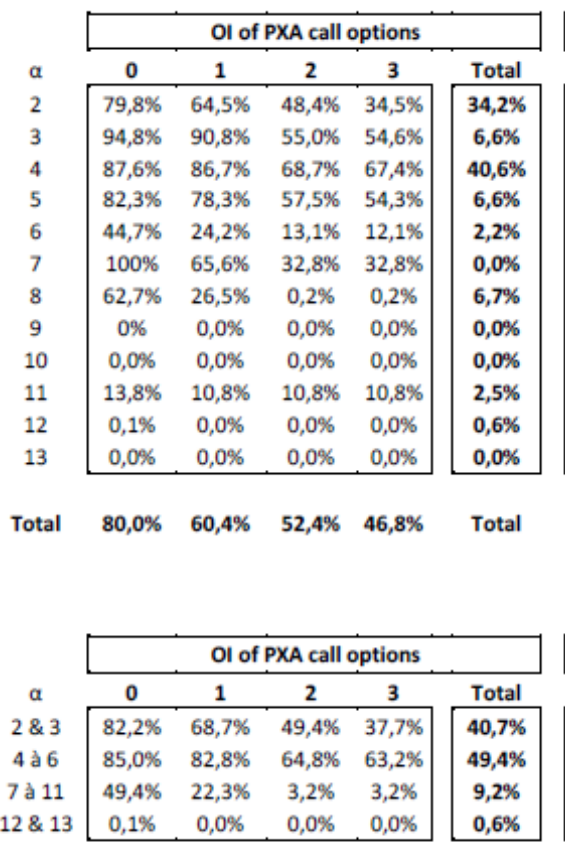

\begin{tabular}{|c|c|c|c|c|}
\hline \multicolumn{5}{|c|}{ OI of PXA put options } \\
\hline 0 & 1 & 2 & 3 & Total \\
\hline $97,1 \%$ & $94,8 \%$ & $93,4 \%$ & $88,8 \%$ & $45,9 \%$ \\
\hline $84,2 \%$ & $84,1 \%$ & $82,6 \%$ & $82,4 \%$ & $7,4 \%$ \\
\hline $94,5 \%$ & $94,2 \%$ & $81,5 \%$ & $80,5 \%$ & $30,7 \%$ \\
\hline $95,2 \%$ & $94,5 \%$ & $83,1 \%$ & $82,6 \%$ & $5,3 \%$ \\
\hline $90,7 \%$ & $57,2 \%$ & $48,7 \%$ & $42,3 \%$ & $1,9 \%$ \\
\hline $80 \%$ & $60,8 \%$ & $52,9 \%$ & $52,9 \%$ & $0,0 \%$ \\
\hline $64,5 \%$ & $55,1 \%$ & $48,2 \%$ & $45,0 \%$ & $6,4 \%$ \\
\hline $100 \%$ & $0 \%$ & $0,0 \%$ & $0,0 \%$ & $0,0 \%$ \\
\hline $0,0 \%$ & $0,0 \%$ & $0,0 \%$ & $0,0 \%$ & $0,0 \%$ \\
\hline $15,7 \%$ & $13,2 \%$ & $13,2 \%$ & $12,8 \%$ & $1,8 \%$ \\
\hline $16,8 \%$ & $11,2 \%$ & $11,2 \%$ & $7,0 \%$ & $0,5 \%$ \\
\hline $0,0 \%$ & $0,0 \%$ & $0,0 \%$ & $0,0 \%$ & $0,0 \%$ \\
\hline
\end{tabular}

$91,1 \% \quad 84,1 \% \quad 82,8 \% \quad 79,9 \% \quad$ Total

(a)

\begin{tabular}{|cccc|c|}
\hline \multicolumn{5}{|c|}{ Ol of PXA call and put options } \\
\hline $\mathbf{0}$ & $\mathbf{1}$ & $\mathbf{2}$ & \multicolumn{1}{c|}{$\mathbf{3}$} & \multicolumn{1}{c|}{ Total } \\
\hline $91,2 \%$ & $84,4 \%$ & $78,0 \%$ & $70,1 \%$ & $\mathbf{4 1 , 1 \%}$ \\
$88,2 \%$ & $86,7 \%$ & $72,0 \%$ & $71,7 \%$ & $\mathbf{7 , 0 \%}$ \\
$91,1 \%$ & $90,6 \%$ & $75,3 \%$ & $74,2 \%$ & $\mathbf{3 4 , 8 \%}$ \\
$89,2 \%$ & $86,9 \%$ & $71,1 \%$ & $69,4 \%$ & $\mathbf{5 , 8 \%}$ \\
$70,3 \%$ & $42,6 \%$ & $32,9 \%$ & $28,9 \%$ & $\mathbf{2 , 0 \%}$ \\
$87,7 \%$ & $62,6 \%$ & $45,4 \%$ & $45,4 \%$ & $\mathbf{0 , 0 \%}$ \\
$63,8 \%$ & $43,0 \%$ & $27,9 \%$ & $26,0 \%$ & $\mathbf{6 , 5 \%}$ \\
$50 \%$ & $0,0 \%$ & $0,0 \%$ & $0,0 \%$ & $\mathbf{0 , 0 \%}$ \\
$0,0 \%$ & $0,0 \%$ & $0,0 \%$ & $0,0 \%$ & $\mathbf{0 , 0 \%}$ \\
$14,7 \%$ & $12,0 \%$ & $12,0 \%$ & $11,8 \%$ & $\mathbf{2 , 1 \%}$ \\
$12,8 \%$ & $9,1 \%$ & $6,0 \%$ & $6,0 \%$ & $\mathbf{0 , 6 \%}$ \\
$0,0 \%$ & $0,0 \%$ & $0,0 \%$ & $0,0 \%$ & $\mathbf{0 , 0 \%}$ \\
\hline
\end{tabular}

$86,6 \% \quad 81,3 \% \quad 70,2 \% \quad 66,3 \%$

\begin{tabular}{|cccc|c|}
\hline \multicolumn{5}{|c|}{ Ol of PXA put options } \\
\hline $\mathbf{0}$ & $\mathbf{1}$ & $\mathbf{2}$ & \multicolumn{1}{c|}{$\mathbf{3}$} & \multicolumn{1}{|c|}{ Total } \\
\hline $95,3 \%$ & $93,3 \%$ & $91,9 \%$ & $87,9 \%$ & \\
$\mathbf{5 3 , 3}$ \\
$94,4 \%$ & $92,4 \%$ & $80,1 \%$ & $78,8 \%$ & $37,9 \%$ \\
$53,9 \%$ & $45,9 \%$ & $40,5 \%$ & $37,9 \%$ & $\mathbf{8 , 3} \%$ \\
$16,8 \%$ & $11,2 \%$ & $11,2 \%$ & $7,0 \%$ & $\mathbf{0 , 5 \%}$ \\
\hline
\end{tabular}

\begin{tabular}{|cccc|c|}
\hline \multicolumn{5}{|c|}{ Ol of PXA call and put options } \\
\hline $\mathbf{0}$ & $\mathbf{1}$ & $\mathbf{2}$ & $\mathbf{3}$ & \multicolumn{1}{|c|}{ Total } \\
\hline $90,7 \%$ & $84,7 \%$ & $77,1 \%$ & $70,4 \%$ & $\mathbf{4 8 , 1 \%}$ \\
$89,9 \%$ & $87,8 \%$ & $72,8 \%$ & $71,4 \%$ & $\mathbf{4 2 , 7 \%}$ \\
$51,9 \%$ & $35,5 \%$ & $24,0 \%$ & $22,6 \%$ & $\mathbf{8 , 7 \%}$ \\
$12,8 \%$ & $9,1 \%$ & $6,0 \%$ & $6,0 \%$ & $\mathbf{0 , 6 \%}$ \\
\hline
\end{tabular}

(b)

Table 15: The distribution of OI of PXA contracts under the 13 maturity scheme (a) and 10

maturity scheme (b) with respect to different values of $\alpha$.

It is straightforward to see that the distribution of OI is less dispersed when maturities are grouped in 5 rather than with 13 PXA contracts. However, we cannot deepen more our analysis as the final impact depends on the variation of the CAC 40 index and the variations of the moneyness scale $\alpha$.

\section{Conclusion}

Our study evidences that CAC 40 index options display liquidity problems when some specific criteria are considered like for example strike price series, expiration dates and moneyness.

Then, we propose (1) to decrease the number of PXA expiration dates from 13 to 10 as 
the number and the volume of open positions are considerably high for long-term expiration date, (2) to keep only 3 strike price series in each strike price scale (one ATM, one OTM and another one ITM), and (3) to reset the PXA strike price at the CAC 40 index value at a pre-agreed point of time $t$ in line with François-Heude and Yousfi (2013) in exchange for deposit into the Clearing House. Under specific conditions, we analyze the distribution of OI regarding the strike price series, expiration dates, ....and we show that these recommendations provide quite satisfying results.

In future research, we would like to study the liquidity of the French equity options and the liquidity of other European and American index options to compare them with the results of the current paper.

In addition, further research should be conducted on when to reset the strike option as the option could be exercised before it matures.

Acknowledgement 1 We thank Gunther Capelle-Blancard, Laurent Deville, Franck Moraux, and seminar participants at the $30^{\text {th }}$ International Conference of the French Finance Association (AFFI) in Lyon and MRM Finance Group for valuable comments on previous draft. We also would like to acknowledge the financial support of MRM, University of Montpellier. 


\section{Appendix}

\section{Appendix $A$ : An overview of PXA option}

$P X A$ contracts are exclusively for European-style exercise options. $P X A$ underlying asset is the $C A C 40$ index. At expiration date, if PXA's holders exercise their options, they are paid automatically the difference between the option strike price and the liquidation value of the $C A C 40$ index multiplied by the number of contracts exercised and the contract unit $(€ 10)^{10}$. Under the demand of clients and to meet international standards, $P X L$ options commonly exchanged since January 1999, had been replaced by $P X A$ options since May $2005^{11}$. They are traded until the third Friday of the expiry month. When the option contract expires, a new expiry cycle is open on the next Monday.

Between May 9, 2005 and May 18, 2007, trades covered 22 PXA open maturities: 3 monthly (each month) and the following 19 quarterly (March, June, September and December cycle) maturities. Since May $21^{\text {st }}$, 2007, PXA trading has covered 13 expiration dates:

\begin{tabular}{|ll|c|}
\hline \multicolumn{1}{|c|}{ Cycle } & \multicolumn{1}{|c|}{ Expiry Months } & Lifetime (Months) \\
\hline 3 Monthly & Every Month & $1 ; 2 ; 3$ \\
7 Quarterly & March. June. September. December & $6 ; 9 ; 12 ; 15 ; 18 ; 21 ; 24$ \\
3 Yearly & December & $36 ; 48 ; 60$ \\
\hline
\end{tabular}

Table 1: Expiration dates of $P X A$ option (prospectusMonep.www.euronext.com)

\footnotetext{
${ }^{10}$ The latter value is the average of the CAC40 index values between 3:30 p.m. and 4:00 p.m.

${ }^{11} P X L$ contract value is equal to the value of the CAC 40 index multiplied by one euro and the tick size is 0,1 index point. $P X A$ value is equal to 10 index points.
} 
Expiration date is the third Friday of the expiration month at 4 p.m. Central European Time. Once maturity expires, a new expiration month is opened the following Monday.

Strike prices are standardized according to symmetric intervals around ATM calls and puts that depend closely on the lifetime of the contract. Strike prices and intervals are function of index point (i.p.). There are 6 CAC 40 index intervals according to the variation of the strike price ${ }^{12}$ :

- Short term maturity: scale A (25 i.p.) and scale B(50 i.p.).

- Medium and long term maturity: scale C (100 i.p.), scale D (200 i.p.), scale E (400 i.p.) and scale F (800 i.p.).

At time maturity $T$, ITM options are automatically exercised unless holders decide not to do so. Then, there is a cash transfer equal to the difference between the option strike and the value of the expiry index, multiplied by the number of contracts exercised and the contract unit $(€ 10)$.

\section{Appendix $B$ : PXA strike price series}

The minimum number of strike price series per interval scale depend on the remaining lifetime of an option. Let consider an option matures at $T$ :

- If the remaining lifetime $(T-t) \leq 1$ month, there are 5 strike prices around the money in interval scale $A$ and 6 others in interval scale $B$.

- If $1<(T-t) \leq 3$ months, there are 3 strike prices in interval scale $B$ and 6 others in scale $C$.

\footnotetext{
${ }^{12}$ For more details, see appendix $A$ and http://www.euronext.com.
} 
- If $3<(T-t) \leq 9$ months, there are 3 strike prices in interval scale $C$ and 6 others in scale $D$.

- If $9<(T-t) \leq 24$ months, there are 3 strike prices in interval scale $D$ and 4 others in scale $E$.

- If $(T-t)>24$ months, there are 3 strike prices in interval scale $E$ and 2 others in scale $F$.

The number of PXA call series is equal to those of PXA put options. Let consider the change of PXA call series over May, 2005 and August, 2012.

\begin{tabular}{|c|c|c|c|c|c|c|}
\hline \multirow[b]{2}{*}{ Scale } & \multirow[b]{2}{*}{ Interval } & \multicolumn{2}{|c|}{$3 \mathrm{M}$} & \multicolumn{2}{|r|}{$7 \mathrm{~T}$} & \multirow{2}{*}{$\begin{array}{c}3 \mathrm{~A} \\
36.48 .60\end{array}$} \\
\hline & & 1 & 2. 3 & 6.9 .12 & 15. 18. 21. 24 & \\
\hline \multirow[b]{2}{*}{$\mathrm{A}$} & \multirow[b]{2}{*}{25} & 01-12 & 01-12 & 03-06-09 & 03-06-09 & 12 \\
\hline & & \multicolumn{2}{|l|}{$\mathrm{ATM} \pm 3$} & & & \\
\hline B & 50 & \pm 3 & $\mathrm{ATM} \pm 3$ & $\mathrm{ATM} \pm 3$ & & \\
\hline $\mathrm{C}$ & 100 & \pm 2 & \pm 4 & \pm 3 & & \\
\hline $\mathrm{D}$ & 200 & \pm 2 & \pm 2 & \pm 2 & $\mathrm{ATM} \pm 2$ & \\
\hline $\mathrm{E}$ & 400 & & \pm 1 & \pm 2 & \pm 2 & $\mathrm{ATM} \pm 1$ \\
\hline $\mathrm{F}$ & 800 & & & & \pm 2 & \pm 1 \\
\hline Call \& & ut options & 21 & 21 & 21 & 13 & 5 \\
\hline
\end{tabular}

Table 1: Strike price series between March $8^{t h}, 2010$ and August $17^{t h}, 2012$. 


\begin{tabular}{|c|c|c|c|c|c|c|}
\hline \multirow[b]{2}{*}{ Scale } & \multirow[b]{2}{*}{ Interval } & \multicolumn{2}{|c|}{$3 \mathrm{M}$} & \multicolumn{2}{|r|}{$7 \mathrm{~T}$} & \multirow{2}{*}{$\begin{array}{c}3 \mathrm{~A} \\
36.48 .60\end{array}$} \\
\hline & & 1 & 2. 3 & 6.9 & 12. 15. 18. 21. 24 & \\
\hline & & 01-12 & 01-12 & 03-06-09 & 03-06-09 & 12 \\
\hline A & 25 & $\mathrm{ATM} \pm 2$ & & & & \\
\hline B & 50 & \pm 3 & $\mathrm{ATM} \pm 1$ & & & \\
\hline $\mathrm{C}$ & 100 & & \pm 3 & $\mathrm{ATM} \pm 1$ & & \\
\hline $\mathrm{D}$ & 200 & & & \pm 3 & $\mathrm{ATM} \pm 1$ & \\
\hline $\mathrm{E}$ & 400 & & & & \pm 2 & $\mathrm{ATM} \pm 1$ \\
\hline $\mathrm{F}$ & 800 & & & & & \pm 1 \\
\hline \multicolumn{2}{|c|}{ Call \& Put options } & 11 & 9 & 9 & 7 & 5 \\
\hline
\end{tabular}

Table 2: Strike price series between May $15^{t h}, 2007$ and March $8^{t h}, 2010$. 


\begin{tabular}{|c|c|c|c|}
\cline { 3 - 4 } \multicolumn{2}{c|}{} & $3 \mathrm{M}$ & $19 \mathrm{~T}$ \\
\hline Scale & Interval & 1.2 .3 & $6.9 . \ldots 60$ \\
\hline A & 25 & $01-12$ & $03-06-09$ \\
\cline { 3 - 4 } B & 50 & ATM \pm 5 & \\
C & 100 & & ATM \pm 5 \\
D & 200 & & \\
E & 400 & & \\
F & & & \\
\hline Call \& Put options & 11 & 11 \\
\hline
\end{tabular}

Table 3: Strike price series between May $9^{\text {th }}, 2005$ and May $21^{\text {st }}, 2007$.

\section{Appendix $C$ : The liquidity effect of maturity categories}

\begin{tabular}{|l|c|c|c|c|c|}
\hline \multicolumn{1}{|c|}{ Maturity category } & 1 & 2 & 3 & 4 & 5 \\
\hline Mean & $43.60 \%$ & $38.88 \%$ & $14.18 \%$ & $2.86 \%$ & $0.47 \%$ \\
Mediane & $44.44 \%$ & $38.82 \%$ & $13.20 \%$ & $1.82 \%$ & $0.00 \%$ \\
Standard deviation & $8.03 \%$ & $9.30 \%$ & $6.13 \%$ & $3.22 \%$ & $0.89 \%$ \\
Max & $61.09 \%$ & $62.65 \%$ & $37.77 \%$ & $17.58 \%$ & $4.91 \%$ \\
Min & $23.65 \%$ & $18.13 \%$ & $4.26 \%$ & $0.00 \%$ & $0.00 \%$ \\
Average cumultaive frequency & $43.60 \%$ & $82.49 \%$ & $96.67 \%$ & $99.53 \%$ & $100 \%$ \\
\hline
\end{tabular}

Table 1: Descriptive statistics on the distribution of PXA call options 


\begin{tabular}{|l|c|c|c|c|c|}
\hline \multicolumn{1}{|c|}{ Maturity category } & 1 & 2 & 3 & 4 & 5 \\
\hline Mean & $43.79 \%$ & $40.29 \%$ & $12.95 \%$ & $2.57 \%$ & $0.41 \%$ \\
Mediane & $43.27 \%$ & $39.01 \%$ & $12.09 \%$ & $1.51 \%$ & $0.07 \%$ \\
Standard deviation & $8.57 \%$ & $9.56 \%$ & $5.02 \%$ & $2.77 \%$ & $0.73 \%$ \\
Max & $61.46 \%$ & $64.44 \%$ & $27.07 \%$ & $15.72 \%$ & $3.59 \%$ \\
Average cumultaive frequency & $43.79 \%$ & $84.08 \%$ & $97.02 \%$ & $99.59 \%$ & $100 \%$ \\
\hline
\end{tabular}

Table 2: Descriptive statistics on the distribution of PXA put options

The distributions of PXA call and put options are quite similar and show the same downward trend from categories 1 to 5 . Long maturity options display illiquidity problems.

The distribution Of PXA volume according to the 5 maturity categories:

\begin{tabular}{|c|c|c|c|c|c|c|c|c|c|c|c|c|c|c|c|c|c|c|}
\hline \multirow[b]{2}{*}{$a \Delta$} & \multicolumn{5}{|c|}{ PXA call options } & \multirow[b]{2}{*}{ Total } & \multicolumn{5}{|c|}{ PXA put options } & \multirow[b]{2}{*}{ Totol } & \multicolumn{5}{|c|}{ PXA call and put options } & \multirow[b]{2}{*}{ Total } \\
\hline & 1 & 2 & 3 & 4 & 5 & & 1 & 2 & 3 & 4 & 5 & & 1 & 2 & 3 & 4 & 5 & \\
\hline 0,4 & $3,6 \%$ & $25,4 \%$ & $63,0 \%$ & $7,9 \%$ & $0,0 \%$ & $0,92 \%$ & $10,5 \%$ & $23,2 \%$ & $59,0 \%$ & $7,3 \%$ & $0,0 \%$ & $0,29 \%$ & $5,6 \%$ & $24,8 \%$ & $61,9 \%$ & $7,8 \%$ & $0,0 \%$ & $0,57 \%$ \\
\hline 0,5 & $6,5 \%$ & $58,6 \%$ & $30,9 \%$ & $4,0 \%$ & $0,0 \%$ & $1,42 \%$ & $10,4 \%$ & $23,0 \%$ & $58,0 \%$ & $8,6 \%$ & $0,0 \%$ & $0,03 \%$ & $6,6 \%$ & $57,6 \%$ & $31,6 \%$ & $4,2 \%$ & $0,0 \%$ & $0,65 \%$ \\
\hline 0,6 & $11,2 \%$ & $50,8 \%$ & $34,7 \%$ & $3,3 \%$ & $0,0 \%$ & $3,23 \%$ & $23,4 \%$ & $19,8 \%$ & $26,3 \%$ & $2,6 \%$ & $27,9 \%$ & $0,04 \%$ & $11,4 \%$ & $50,3 \%$ & $34,6 \%$ & $3,3 \%$ & $0,4 \%$ & $1,46 \%$ \\
\hline 0,7 & $18,4 \%$ & $53,0 \%$ & $26,7 \%$ & $1,7 \%$ & $0,2 \%$ & $8,91 \%$ & $39,4 \%$ & $29,5 \%$ & $18,2 \%$ & $5,5 \%$ & $7,4 \%$ & $0,21 \%$ & $19,0 \%$ & $52,3 \%$ & $26,4 \%$ & $1,8 \%$ & $0,4 \%$ & $4,08 \%$ \\
\hline 0,8 & $32,2 \%$ & $53,1 \%$ & $13,3 \%$ & $1,3 \%$ & $0,1 \%$ & $25,13 \%$ & $32,9 \%$ & $30,1 \%$ & $23,2 \%$ & $12,5 \%$ & $1,3 \%$ & $1,03 \%$ & $32,2 \%$ & $52,0 \%$ & $13,7 \%$ & $1,9 \%$ & $0,2 \%$ & $11,75 \%$ \\
\hline 0,9 & $57,9 \%$ & $31,6 \%$ & $9,0 \%$ & $1,4 \%$ & $0,2 \%$ & $47,10 \%$ & $47,5 \%$ & $29,3 \%$ & $18,5 \%$ & $4,1 \%$ & $0,6 \%$ & $11,30 \%$ & $55,5 \%$ & $31,0 \%$ & $11,2 \%$ & $2,0 \%$ & $0,3 \%$ & $27,21 \%$ \\
\hline 1,0 & $47,9 \%$ & $24,1 \%$ & $14,5 \%$ & $11,3 \%$ & $2,2 \%$ & $12,27 \%$ & $56,7 \%$ & $31,5 \%$ & $8,1 \%$ & $3,1 \%$ & $0,6 \%$ & $37,63 \%$ & $54,9 \%$ & $30,0 \%$ & $9,4 \%$ & $4,8 \%$ & $0,9 \%$ & $26,35 \%$ \\
\hline 1,1 & $33,3 \%$ & $30,4 \%$ & $21,3 \%$ & $8,7 \%$ & $6,3 \%$ & $0,61 \%$ & $46,6 \%$ & $42,1 \%$ & $10,2 \%$ & $0,9 \%$ & $0,2 \%$ & $21,81 \%$ & $46,3 \%$ & $41,9 \%$ & $10,5 \%$ & $1,1 \%$ & $0,3 \%$ & $12,39 \%$ \\
\hline 1,2 & $21,0 \%$ & $24,9 \%$ & $40,7 \%$ & $10,5 \%$ & $2,9 \%$ & $0,12 \%$ & $32,7 \%$ & $53,3 \%$ & $12,7 \%$ & $1,1 \%$ & $0,1 \%$ & $10,84 \%$ & $32,6 \%$ & $53,1 \%$ & $12,9 \%$ & $1,2 \%$ & $0,1 \%$ & $6,08 \%$ \\
\hline 1,3 & $13,7 \%$ & $21,6 \%$ & $41,8 \%$ & $13,4 \%$ & $9,5 \%$ & $0,06 \%$ & $23,4 \%$ & $58,3 \%$ & $16,4 \%$ & $1,8 \%$ & $0,0 \%$ & $6,23 \%$ & $23,4 \%$ & $58,0 \%$ & $16,6 \%$ & $1,9 \%$ & $0,1 \%$ & $3,49 \%$ \\
\hline 1,4 & $2,4 \%$ & $18,5 \%$ & $21,2 \%$ & $20,2 \%$ & $37,7 \%$ & $0,05 \%$ & $17,9 \%$ & $60,7 \%$ & $19,3 \%$ & $2,0 \%$ & $0,0 \%$ & $4,12 \%$ & $17,8 \%$ & $60,3 \%$ & $19,3 \%$ & $2,2 \%$ & $0,4 \%$ & $2,31 \%$ \\
\hline 1,5 & $2,4 \%$ & $8,8 \%$ & $62,9 \%$ & $26,0 \%$ & $0,0 \%$ & $0,03 \%$ & $15,2 \%$ & $61,2 \%$ & $20,3 \%$ & $3,2 \%$ & $0,2 \%$ & $2,29 \%$ & $15,1 \%$ & $60,7 \%$ & $20,7 \%$ & $3,4 \%$ & $0,2 \%$ & $1,29 \%$ \\
\hline 1,6 & $11,4 \%$ & $31,2 \%$ & $51,7 \%$ & $5,6 \%$ & $0,0 \%$ & $0,15 \%$ & $8,9 \%$ & $52,0 \%$ & $34,4 \%$ & $4,3 \%$ & $0,3 \%$ & $4,17 \%$ & $9,0 \%$ & $51,4 \%$ & $34,9 \%$ & $4,4 \%$ & $0,3 \%$ & $2,39 \%$ \\
\hline
\end{tabular}

Table 1: The distribution of the volume of PXA series according to the maturity

$$
\text { categories }(\alpha \Delta= \pm 0,1) \text {. }
$$

The distribution Of PXA OI according to maturity categories: 


\begin{tabular}{|c|c|c|c|c|c|c|c|c|c|c|c|c|c|c|c|c|c|c|}
\hline \multirow[b]{2}{*}{$\alpha \Delta$} & \multicolumn{5}{|c|}{ PXA call options } & \multirow[b]{2}{*}{ Total } & \multicolumn{5}{|c|}{ PXA put options } & \multirow[b]{2}{*}{ Total } & \multicolumn{5}{|c|}{ PXA call and put options } & \multirow[b]{2}{*}{ Total } \\
\hline & 1 & 2 & 3 & 4 & 5 & & & 2 & 3 & 4 & 5 & & 1 & 2 & 3 & 4 & 5 & \\
\hline 0,4 & $13,1 \%$ & $20,4 \%$ & $39,7 \%$ & $26,2 \%$ & $0,6 \%$ & $13,26 \%$ & $8,6 \%$ & $16,4 \%$ & $38,7 \%$ & $35,4 \%$ & $1,0 \%$ & $8,95 \%$ & $11,2 \%$ & $18,7 \%$ & $39,3 \%$ & $30,1 \%$ & $0,8 \%$ & $11,00 \%$ \\
\hline 0,5 & $19,5 \%$ & $24,8 \%$ & $39,6 \%$ & $15,3 \%$ & $0,8 \%$ & $5,05 \%$ & $12,2 \%$ & $18,3 \%$ & $43,1 \%$ & $23,9 \%$ & $2,5 \%$ & $2,52 \%$ & $16,9 \%$ & $22,5 \%$ & $40,8 \%$ & $18,3 \%$ & $1,4 \%$ & $3,73 \%$ \\
\hline 0,6 & $18,7 \%$ & $23,6 \%$ & $41,9 \%$ & $15,0 \%$ & $0,7 \%$ & $6,96 \%$ & $10,5 \%$ & $14,7 \%$ & $44,5 \%$ & $28,2 \%$ & $2,1 \%$ & $3,00 \%$ & $16,1 \%$ & $20,8 \%$ & $42,7 \%$ & $19,3 \%$ & $1,1 \%$ & $4,89 \%$ \\
\hline 0,7 & $22,3 \%$ & $28,5 \%$ & $35,9 \%$ & $12,0 \%$ & $1,2 \%$ & $10,14 \%$ & $13,8 \%$ & $16,7 \%$ & $43,3 \%$ & $24,4 \%$ & $1,8 \%$ & $3,62 \%$ & $19,9 \%$ & $25,2 \%$ & $38,0 \%$ & $15,5 \%$ & $1,3 \%$ & $6,73 \%$ \\
\hline 0,8 & $26,7 \%$ & $32,1 \%$ & $28,8 \%$ & $11,3 \%$ & $1,1 \%$ & $13,95 \%$ & $16,8 \%$ & $18,1 \%$ & $39,8 \%$ & $23,3 \%$ & $2,0 \%$ & $4,99 \%$ & $23,9 \%$ & $28,2 \%$ & $31,9 \%$ & $14,7 \%$ & $1,4 \%$ & $9,25 \%$ \\
\hline 0,9 & $30,0 \%$ & $26,7 \%$ & $26,9 \%$ & $14,0 \%$ & $2,4 \%$ & $15,95 \%$ & $21,1 \%$ & $21,8 \%$ & $33,6 \%$ & $19,9 \%$ & $3,6 \%$ & $8,85 \%$ & $26,6 \%$ & $24,8 \%$ & $29,4 \%$ & $16,2 \%$ & $2,9 \%$ & $12,23 \%$ \\
\hline 1,0 & $20,2 \%$ & $20,8 \%$ & $30,1 \%$ & $23,7 \%$ & $5,2 \%$ & $11,02 \%$ & $28,7 \%$ & $26,0 \%$ & $24,8 \%$ & $16,8 \%$ & $3,7 \%$ & $13,32 \%$ & $25,0 \%$ & $23,7 \%$ & $27,1 \%$ & $19,8 \%$ & $4,3 \%$ & $12,23 \%$ \\
\hline 1,1 & $12,3 \%$ & $15,6 \%$ & $32,9 \%$ & $30,7 \%$ & $8,4 \%$ & $6,73 \%$ & $29,9 \%$ & $26,2 \%$ & $24,7 \%$ & $15,3 \%$ & $3,9 \%$ & $12,39 \%$ & $24,1 \%$ & $22,7 \%$ & $27,4 \%$ & $20,4 \%$ & $5,4 \%$ & $9,70 \%$ \\
\hline 1,2 & $8,7 \%$ & $12,4 \%$ & $35,8 \%$ & $34,4 \%$ & $8,8 \%$ & $4,65 \%$ & $25,8 \%$ & $26,7 \%$ & $26,8 \%$ & $17,1 \%$ & $3,6 \%$ & $9,77 \%$ & $20,6 \%$ & $22,4 \%$ & $29,5 \%$ & $22,3 \%$ & $5,2 \%$ & $7,33 \%$ \\
\hline 1,3 & $7,6 \%$ & $12,8 \%$ & $35,9 \%$ & $36,0 \%$ & $7,5 \%$ & $3,42 \%$ & $21,7 \%$ & $26,9 \%$ & $30,7 \%$ & $17,9 \%$ & $2,8 \%$ & $7,51 \%$ & $17,6 \%$ & $22,8 \%$ & $32,2 \%$ & $23,2 \%$ & $4,2 \%$ & $5,56 \%$ \\
\hline 1,4 & $7,6 \%$ & $12,9 \%$ & $39,7 \%$ & $34,0 \%$ & $5,9 \%$ & $2,58 \%$ & $20,6 \%$ & $26,4 \%$ & $33,4 \%$ & $17,6 \%$ & $2,0 \%$ & $5,94 \%$ & $16,9 \%$ & $22,6 \%$ & $35,1 \%$ & $22,2 \%$ & $3,1 \%$ & $4,34 \%$ \\
\hline 1,5 & $6,8 \%$ & $16,0 \%$ & $36,2 \%$ & $37,4 \%$ & $3,5 \%$ & $1,93 \%$ & $19,4 \%$ & $26,5 \%$ & $32,9 \%$ & $19,4 \%$ & $1,8 \%$ & $4,58 \%$ & $15,9 \%$ & $23,6 \%$ & $33,8 \%$ & $24,4 \%$ & $2,3 \%$ & $3,32 \%$ \\
\hline 1,6 & $8,3 \%$ & $14,0 \%$ & $34,8 \%$ & $41,2 \%$ & $1,7 \%$ & $4,36 \%$ & $16,3 \%$ & $25,3 \%$ & $37,5 \%$ & $19,8 \%$ & $1,1 \%$ & $14,57 \%$ & $14,6 \%$ & $22,9 \%$ & $36,9 \%$ & $24,4 \%$ & $1,3 \%$ & $9,71 \%$ \\
\hline
\end{tabular}

Table 2: The distribution of the OI of PXA series according to the maturity categories

$$
(\alpha \Delta= \pm 0,1) .
$$

\section{References}

[1] Amihud. Y., and H. Mendelson, (1986), "Asset Pricing and the Bid-Ask Spread", Journal of Financial Economics, 17, 223-49.

[2] Amihud. Y., and H. Mendelson, (1991), "Liquidity, Maturity and the Yields on US Treasury Securities", Journal of Finance, 46, 1411-25.

[3] Amihud. Y., H. Mendelson, and L.H. Pedersen, (2005), "Liquidity and Asset Prices", Foundations and Trends in Finance, 1, 269-364.

[4] Black. F. and M. Scholes, (1973), "The pricing of options and corporate liabilities", Journal of political Economics, 81, 637-659.

[5] Bollen. N.P.. and R.E. Whaley. (2004). "Does Net Buying Pressure Affect the Shape of Implied Volatility Functions ?", Journal of Finance, 59, 711-53. 
[6] Brennan. M.J. and A. Subrahmanyam, (1996), "Market Microstructure and Asset Pricing: On the Compensation for Illiquidity in Stock Returns", Journal of Financial Economics, 41, 441-64.

[7] Capelle-Blancard G. and M. Chaudhury, (2001), "Efficiency tests of the French index (CAC 40) option market", McGill Finance Research Centre Working Paper SSRN, http://papers.ssrn.com/sol3/papers.cfm?abstract_id=283695.

[8] Capelle-Blancard G. and M. Chaudhury, (2007), "Price clustering in the CAC 40 index options market", Applied Financial Economics, 7, 1201-1210.

[9] Chen J.Y.. and J.Y. Wang, (2011), "The valuation of Forward-start Rainbow options", in the 2011 FMA European Conference. Porto. Portugal. June 8-10.

[10] Cheng. W.Y. and S. Zhang. (2000), The analytics of reset options. Journal of derivatives, 8, 59-71.

[11] Cho. Y.. and R. Engle. (1999), "Modeling the Impact of Market Activity on Bid-Ask Spread in the Options Market". NBER Working Paper No. 7331. http://www.nber.org/papers/w7331.pdf?new_window=1.

[12] Cont R. and J. da Fonseca. (2002), "Dynamics of implied volatility surfaces", Quantitative Finance, 2 (1), 45-60.

[13] Cox. J.C.. S. Ross and M. Rubinstein. (1979), "Option pricing: A simplified Approach", Journal of Financial Economics, 7, 229-264.

[14] Datar. V.T., N.Y. Naik, and R. Radcliffe, (1998), "Liquidity and Asset Returns: An Alternative Test", Journal of Financial Markets. 1. 203-19.

[15] Deville. L. and F. Riva, (2007), "Liquidity and Arbitrage in Options Markets: A Survival Analysis Approach", Review of Finance, 11 (3), 497-525. 
[16] Deville. L., (2004), "Time to Efficiency of the French CAC 40 Index Options Market", EFMA 2004 Basel Meetings Paper, http://papers.ssrn.com/sol3/papers.cfm?abstract_id=498942.

[17] Easley. D.. and M. O'Hara, (2003), "Microstructure and Asset Pricing", in: G. Constantinides. M. Harris and R. Stulz (eds.), Handbook of Financial Economics. Amsterdam: Elsevier Science Publishers.

[18] Eleswarapu. V.R., (1997), "Cost of Transacting and Expected Returns in the Nasdaq Market", Journal of Finance, 52, 2113-27.

[19] François-Heude. A. and O. Yousfi, (2013). "A generalization of Gray and Whaley's reset option", working paper, presented at the $30^{\text {th }}$ AFFI conference. paper.http://events.em-lyon.com/AFFI/Papers/47.pdf.

[20] Frey. R.. (1998), "Perfect Option Hedging for a Large Trader", Finance and Stochastics, $2,115-41$

[21] Garleanu. N., L.H. Pedersen., and A.M. Poteshman, (2009), "Demand-based Option Pricing", Review of Financial Studies, 22, 4259-4299.

[22] Gray. S.F. and R.E. Whaley, (1999), "Reset Put Options: Valuation. Risk Charactheristics. and an Application", Australian Journal of Management, 24 (1), 1-20.

[23] Gregoriou. A., (2011), "The Liquidity Effects of Revisions to the CAC40 Stock Index", Applied Financial Economics, 21(4), 333-341.

[24] Guo. J.H. and M.W. Hung. (2008). A generalization of Rubinstein's "Pay Now. Choose Later". Journal of Futures Markets, 28 (5), 488-515

[25] Handa P. and Schwartz R.S., (1996), "How best to Supply Liquidity to a Securities Market", The Journal of Portfolio Management, 22, 44-51. 
[26] Haug. E. and J. Haug. (2001), "The collector: Who's on first base?", Wilmott Magazine. http://www.wilmott.com/pdfs/010721_collector_02.pdf.

[27] Haugen. R.A. and N.L. Baker, (1996), "Commonality in the Determinants of Expected Stock Returns", Journal of Financial Economics, 41, 401-39.

[28] Johnson. H.. (1987), "Options on the maximum or the minimum of several assets" Journal of Financial and Quantitatives Analysis, 22, 277-283.

[29] Kamara. A.. (1994), "Liquidity, Taxes and Short-term Treasury Yields", Journal of Financial and Quantitative Analysis, 29, 403-17.

[30] Kamara. A. and T. Miller, (1995), "daily and intradaily tests of put-call parity", Journal of Financial and Quantitative Analysis, 30, 519-539.

[31] Kermiche. L., (2009), "Dynamics of Implied Distributions: Evidence from the CAC 40 Options Market", Finance, 30 (2), 64-103.

[32] Kermiche. L., (2008), "Modélisation de la surface de volatilité implicite par processus à sauts", Finance, 29 (2), 57-101.

[33] Lia. S.L. and C.W. Wang, (2003), "The valuation of reset options with multiple strike resets and reset dates", Journal of Futures Markets, 23, 87-107.

[34] Liu. W., (2006), "A Liquidity-Augmented Capital Asset Pricing Model", Journal of financial Economics, 82(3), 631-671.

[35] Margrabe. W., (1978), "The value of an option to exchange one asset for another", Journal of Finance, 33, 177-186.

[36] Marcellino. G. and A. Zanette, (2011), "pricing cliquet options by tree methods", Computational Management Science, 8 (1-2), 125-135. 
[37] Mittnik. S., and S. Rieken, (2000), "Put-Call Parity and the Informational Efficiency of the German DAXIndex Options Markets", International Review of Financial Analysis, $9,259-279$

[38] Rendleman. R.J. and B.J. Bartter, (1980), "The pricing of options on debt securities", Journal of Financial and Quantitative Analysis, 15, 11-24.

[39] Riva. F. and L. Deville, (2005), "The determinants of the time to efficiency in options markets : a survival analysis approach", FMA European Conference, http://halshs.archives-ouvertes.fr/halshs-00163231/.

[40] Roll. R., E. Schwartz and A. Subrahmanyam, (2007). "Liquidity and the Law of one price: The case of the futures/cash basis", Jouranl of Finance, 62, 2201-2234.

[41] Rubinstein. M.. (1991). Pay now. choose later. Risk. Vol. 4. p.13.

[42] Stultz. R., (1991), "Options on the minimum or the maximum of two risky assets: analysis and applications", Journal of Financial Economics, 10, 161-185.

[43] Windcliff. H.A., P.A. Forsyth, and K.R. Vetzal, (2006), "Numerical Methods for Valuing Cliquet Options."Working paper, https://cs.uwaterloo.ca/ paforsyt/cliquet.pdf. 